\title{
Loss of Supernumerary Axons During Neuronal Morphogenesis ${ }^{1}$
}

\author{
R. DAVID HEATHCOTE ${ }^{2}$ AND PETER B. SARGENT \\ Department of Cell Biology, Stanford University School of Medicine, Stanford, California 94305
}

\begin{abstract}
The morphogenesis of individual neurons was investigated in the cardiac ganglion of the frog. Intracellular injection of horseradish peroxidase shows that mature neurons lack dendrites and have a single axon. Early in development, more than half of the neurons are multipolar and have as many as four processes emanating from their cell body. The most likely mechanism for the developmental transformation of larval neurons is that the supernumerary processes are pruned from the cell body.

Supernumerary processes in larval neurons have features characteristic of axons. The processes of larval neurons can be highly branched and extend throughout the target with distinctive varicosities along the length of each process. Electron microscopy shows that all processes of individually injected cells contain clusters of vesicles apposed to active zones. Thus, the larval cardiac ganglion neuron is capable of extending more than one axon from its cell body.
\end{abstract}

During development, neurons differentiate into distinctive cell shapes. This is achieved by the extension of processes from the cell body and by their branching. The elaboration of processes does not necessarily complete the morphogenesis of the cell. Many neurons sprout collateral processes which are subsequently eliminated to attain the mature cell shape (e.g., Cajal, 1960). The concerted action of these morphogenetic events during development is important in establishing the structural organization of neural assemblies (Stanfield, 1984) and can have functional consequences, as in the retraction of axons from cells receiving excessive polyneuronal innervation (Purves and Lichtman, 1980).

One approach toward understanding the cellular events that underlie the morphogenesis of individual neurons is to ask how a simple neuron attains its definitive shape. Mature neurons in the cardiac ganglion of the frog Xenopus laevis have a single axon, which typically remains unbranched for some distance from the cell body. On the other hand, early in development, cardiac neurons can have up to four highly branched processes emanating from their cell body. Thus, the morphology of neurons appears to change dramatically as supernumerary processes disappear. Electron microscopy of individual larval cells shows that the multipolar processes

Received October 22, 1984; Revised December 7, 1984; Accepted December 10, 1984

\footnotetext{
${ }^{1}$ We wish to thank Dale Purves and Carla Shatz for reading and criticizing the manuscript. This work was supported by the American Heart Association, California Affiliate, by the National Science Foundation, and by the March of Dimes Birth Defects Foundation.

${ }^{2}$ To whom correspondence should be sent at his present address: Department of Physiology C240, I Iniversity of Colorado School of Medicine, 4200 E. 9th Ave., Denver, CO 80262.
}

cannot be distinguished from one another and appear to be axons, since they contain clusters of synaptic vesicles adjacent to active zones. Therefore, immature cardiac neurons are capable of sustaining more than one axon during a particular stage of their differentiation. (A portion of this work has been published in abstract form; Heathcote and Sargent, 1983.)

\section{Materials and Methods}

Animals from our Xenopus breeding colony were staged (Nieuwkoop and Faber, 1967) and anesthetized, and their hearts were removed. The atrium (or interatrial septum) was pinned to a thin layer of Sylgard resin on a glassbottomed chamber (McMahan and Kuffler, 1971). The preparation was kept in $70 \% \mathrm{~L}-15$ medium with $10 \mathrm{~mm} \mathrm{Ca}^{+2}$ to facilitate microelectrode penetration and with $2.5 \mu \mathrm{g} / \mathrm{ml}$ Verapamil (Knoll Pharmaceutical Co., Whippany, $\mathrm{NJ}$ ) to prevent movement. The ganglion was examined with Nomarski optics, and individual neurons were penetrated with micropipettes filled with $4 \%$ horseradish peroxidase $(\mathrm{HRP})$ in $0.2 \mathrm{M}$ potassium acetate. $\mathrm{HRP}$ was iontophoresed into the cell by applying 1 -nA pulses at $50 \%$ duty cycle for approximately 5 min. HRP was allowed to diffuse overnight at $4^{\circ} \mathrm{C}$ and was then visualized with standard histochemical techniques.

For electron microscopy, the hearts were embedded in a thin layer of plastic. The neurons were traced with a camera lucida and photographed. Serial thick sections $(2 \mu \mathrm{m})$ of the heart were taken, and the reaction product in appropriate scctions was traccd, photographed, and reembedded for thin sectioning and examination by electron microscopy (see Robson and Mason, 1979).

\section{Results}

Cardiac ganglion neurons are located in the atrium of the heart along branches of the vagus nerve. These neurons are formed over a prolonged period of time and accumulate in the heart at a constant rate (Heathcote and Sargent, 1984). Thus, at any particular time during the early phases of development, neurons at all stages of their differentiation are present in the heart.

Neuronal shape. Injection of HRP shows that adult cardiac ganglion neurons have a simple morphology. The neuronal cell body is ellipsoidal and has no dendrites (Fig. 1A). A single axon originates from the cell body, joins a branch of the vagal nerve trunk, and ordinarily courses along the nerve for many hundreds of microns without branching (Fig. 1C). Each of 116 adult neurons examined was monopolar, and only $10 \%$ branched within $400 \mu \mathrm{m}$ of the cell body (Table I).

Neurons in larval ganglia vary greatly in shape and can have extremely complex morphologies. The cell body of HRP-injected larval neurons can have up to four primary processes (Fig. 1B). These processes may extend for quite some distance from the cell body and branch profusely throughout the entire atrium (Fig. 1D). Fifty-three percent of the 140 neurons examined in animals between 1 and 3 weeks of development (stages 48 to 52) were multipolar, compared to $0 \%$ in the adult (Table I). In addition, $73 \%$ of the larval neurons had secondary branches compared with $10 \%$ in the adult (Table I). Thus, the constituents of the ganglion change dramatically during development.

A spectrum of neuronal types, ranging from monopolar to multipolar cells, coexist in larval ganglia. The multiaxonal cells can branch 

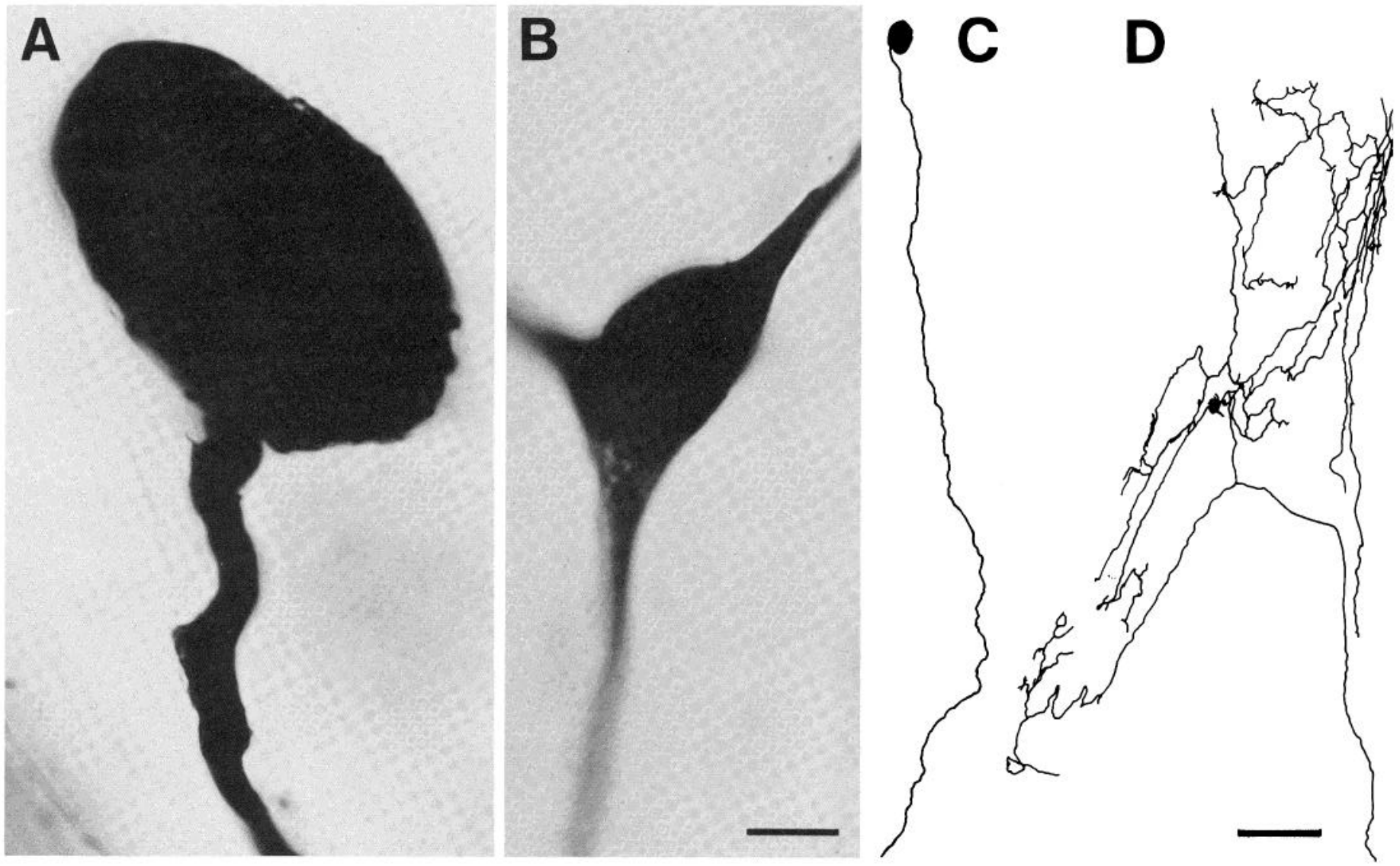

Figure 1. Morphology of adult and larval cardiac ganglion neurons. Photomicrographs $(A$ and $B)$ of the primary branching and camera lucida tracings $(C$ and $D)$ of the secondary branching in mature and larval neurons stained by iontophoretic injection of HRP. A shows the monopolar morphology that is characteristic of adult neurons. $B$ shows a tripolar neuron within a larval heart. More than half of the larval neurons examined were multipolar. In $C$, the axon of another adult neuron is seen to course for a long distance without branching. $D$, A larval neuron that branches extensively and courses throughout an appreciable fraction of the atrium. Calibration: $A$ and $B, 10 \mu \mathrm{m} ; C$ and $D, 100 \mu \mathrm{m}$.

TABLE I

Morphology of larval and mature neurons

\begin{tabular}{lcc}
\hline & Larval Neurons & Mature Neurons \\
\hline Primary processes per cell & $1.7 \pm 0.7^{b}$ & $1.0 \pm 0$ \\
Fraction of cells multipolar & $53 \%$ & $0 \%$ \\
Fraction of cells having sec- & $73 \%$ & $10 \%$ \\
$\quad$ ondary processes & \\
Number of cells examined & 140 & 116 \\
\hline
\end{tabular}

${ }^{a}$ Primary processes are those emanating from the cell body.

${ }^{b}$ Mean \pm SD.

${ }^{\circ}$ Branching of primary processes within approximately $400 \mu \mathrm{m}$ of the cell body.

extensively throughout the entire atrium, whereas monopolar neurons have single axons that remain unbranched for some distance from the cell body (Fig. 2). During the larval stages examined, neurons continue to be born and differentiate (Heathcote and Sargent, 1984). The different morphological types observed may represent intermediate stages in the acquisition of the mature cell shape.

Larval neurons with complex shapes presumably arise from simple, rounded postmitotic cells. Thus, a period of extensive axonal outgrowth and branching is expected of larval neurons. Examination of injected larval neurons (Fig. 2) reveals the structural correlates of growth. Fine, unbranched filopodia are present on neuronal cell bodies, as well as on their axons (Fig. $3 A$ ). In addition, secondary and tertiary branches often terminate in typical growth cones (Fig. $3 B$ ). These specializations are characteristics of actively growing neurons and are present in the complex larval cells.
It is possible that multipolar neurons persist but escape detection because they represent only a small fraction of the adult neuronal population. To determine the likelihood of such an event, the numbers of multipolar neurons at the larval stages studied were counted, and the probability that they would be missed in an adult ganglion was calculated. Between 1 and 3 weeks of development, there is an average of about 90 neurons (R. D. Heathcote and P. B. Sargent, manuscript in preparation), of which $53 \%$ are multipolar (Table I). Thus, 48 multipolar cells are present which are postulated to persist in the adult. The average number of cells present in mature, adult frogs is approximately 1,300 (R. D. Heathcote and P. B. Sargent, manuscript in preparation). From this population, 116 neurons were filled, and none were found to be multipolar. If it is equally likely that multipolar and monopolar cells are filled, the probability of "missing" a multipolar cell having sampled the population 116 times is given by a binomial distribution:

$$
P(k)=\frac{n !}{k !(n-k) !} p^{k}(1-p)^{n-k}
$$

where $k=$ the number of successes $(0), n=$ the sample size drawn with replacement (116), and $p=$ the probability of success in one trial $(48 / 1300=0.037$; Parzen, 1960$)$. Since $P(0)$ is 0.01 , it is highly unlikely that multipolar cells persist into adult life yet remain undetected. Thus, there must be fewer multipolar cells in adults than in larvae.

Larval neurons are multiaxonal. Inasmuch as mature neurons have a single axon, it may be that only one process of multipolar neurons in larvae is axonal. Mature axons have varicosities along their length which contain clusters of vesicles situated next to active 


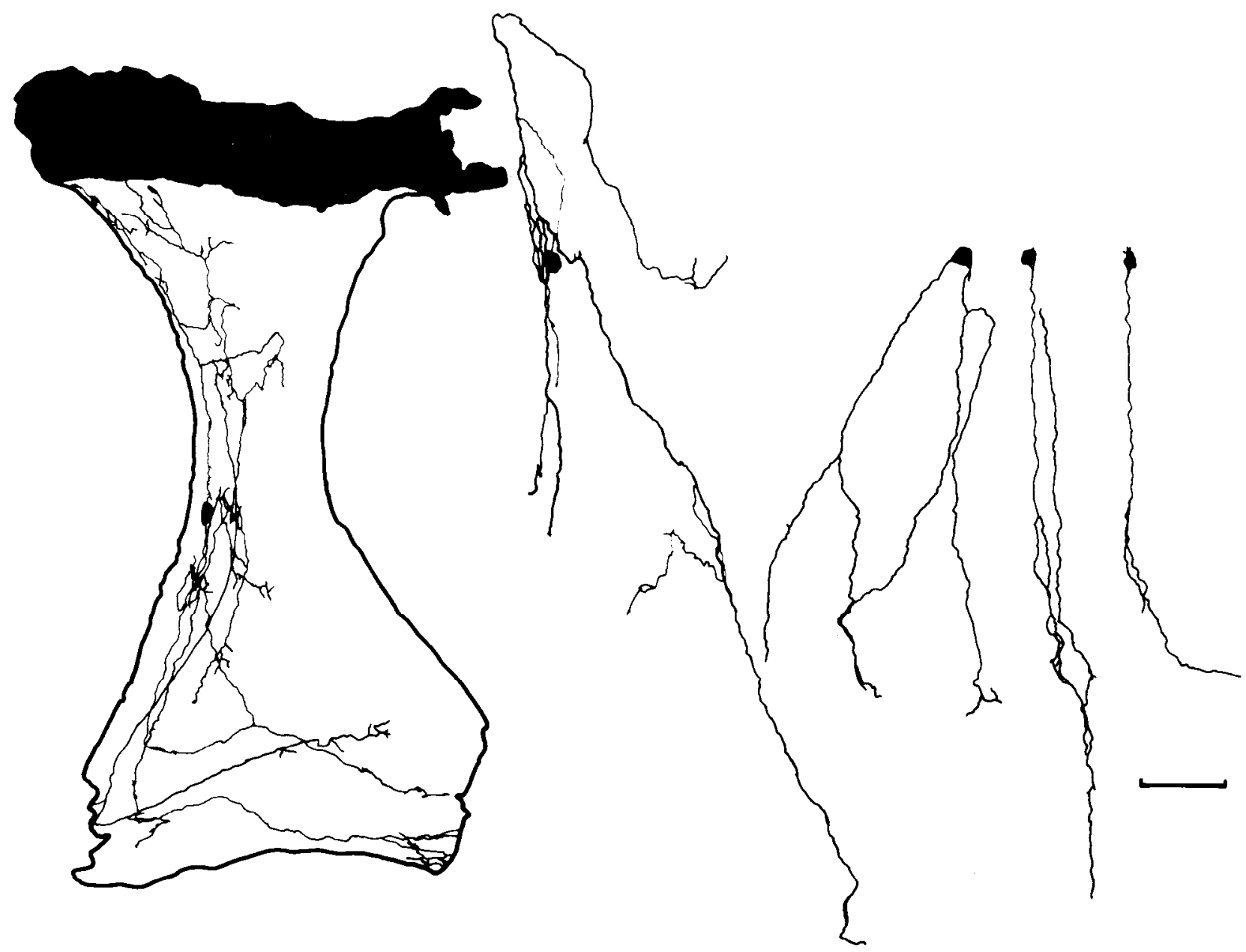

Figure 2. Range of larval neuronal morphologies. Camera lucida tracings of a set of HRP-filled larval neurons arranged in order of their complexity. The complete range of morphologies is apparent, from multipolar cells with widespread secondary branching to monopolar cells with relatively little branching. All of these neurons are seen at a time during which there is extensive neuronal proliferation and differentiation. Thus, the different types may represent stages in the morphogenesis of these neurons. Calibration: $100 \mu \mathrm{m}$. 

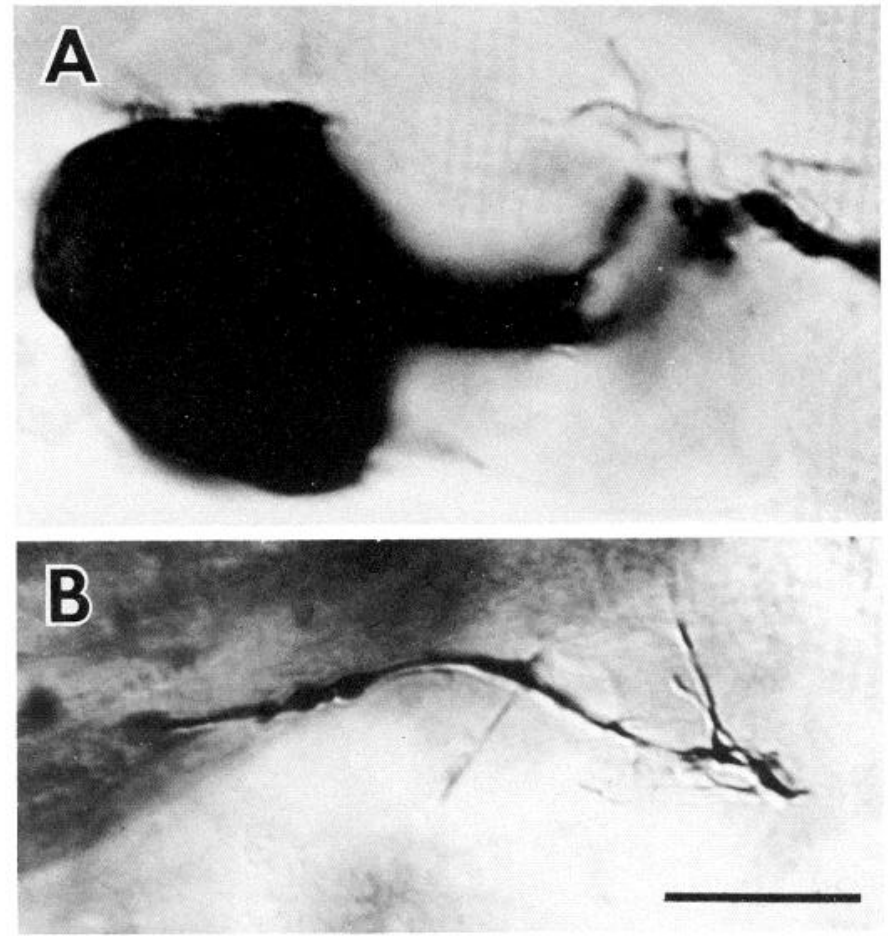

Figure 3. Photomicrographs of larval structures that are characteristic of actively growing neurons. In $A$, prominent filopodia are seen emerging from an axon. Filopodia are also commonly seen extending from larval cell bodies. In $B$, a growth cone of a larval cell can be seen. The axonal branches of larval neurons often terminate in growth cones. Calibration: $A$ and $B, 10 \mu \mathrm{m}$.

zones (McMahan and Kuffler, 1971). ${ }^{3}$ Varicosities are often seen in larval neurons, and in fact can be present in each process of individual multipolar cells (Fig. 4A). Are varicosities the site of vesicle accumulation in larval neurons, and do both processes of bipolar cells have this axonal characteristic? A single neuron was injected with HRP in each of several ganglia, and three bipolar neurons with spatially distinct processes were chosen for analysis. Both processes of the cell shown in Figure $4 A$ have extensive arborizations and bear many varicosities. Varicosities of each process were examined with electron microscopy and were found to contain clusters of vesicles apposed to electron dense patches of membrane presumed to be active zones (Fig. $4, B$ and $C$ ). Consistent results were obtained from the other two bipolar cells examined. Consequently, the multipolar processes of these cells are similar and have the ultrastructural characteristics of axons.

\section{Discussion}

Early in development, cardiac ganglion neurons are multiaxonal, with secondary, tertiary, and higher-order branches extending throughout the heart. In the adult, however, the neurons have but a single axon, which remains unbranched for a considerable distance from the cell body. Figure 5 illustrates three possible mechanisms that may account for the loss of neuronal processes. The first possibility is that multipolar neurons undergo selective cell death. Alternatively, individual neurons might change, either by the differential growth of parts of the neuron or by the withdrawal of supernumerary processes. All of these mechanisms are important in the morphogenesis of different neurons, and each possibility is discussed below.

Cell death is an important mechanism in the morphogenesis of

\footnotetext{
${ }^{3}$ The varicosities rarely come into close contact with cardiac muscle and induce postsynaptic specializations (Hartzell, 1980). The transmitter, acetylcholine, has a humoral effect on the target muscle (Loewi, 1921).
}

the nervous system (Cowan et al., 1984). In the cardiac ganglion, cell death could act selectively upon multipolar neurons to effect the morphogenetic change observed (Fig. 5). The extent of selective cell death would have to be substantial, since more than half of the larval neurons are multipolar, and an even higher percentage have branching patterns rarely seen in mature animals. Dying neurons have not been observed in living cardiac ganglia viewed with Nomarski optics, despite the fact that Nomarski optics readily permits identification of dying neurons in invertebrates (Sulston and Horvitz, 1977), as well as cardiac neurons damaged by microelectrodes ( $R$. D. Heathcote and P. B. Sargent, unpublished data). Likewise, necrotic neuronal nuclei have not been seen in fixed and sectioned tissue. On the contrary, cardiac ganglion neurons continue to be born and differentiate throughout larval life (R. D. Heathcote and P. B. Sargent, manuscript in preparation). Thus, the range of neuronal types observed in larvae (Fig. 2) may represent different stages in the differentiation of these neurons. If all neurons pass through a multipolar stage in their differentiation, then selective cell death cannot play a role in the loss of multipolar neurons.

In the absence of cell death, the morphogenesis of multipolar neurons must involve remodelling of neuronal shape, perhaps through differential cell growth (Fig. 5). A multipolar neuron might become monopolar by preferentially adding membrane between the cell body and axons, thus becoming connected by a single stalk to the axonal processes. This intercalary growth is the mechanism by which dorsal root ganglion neurons (Tennyson, 1965) and cerebellar granule cells (Rakic, 1971) achieve their mature shape. Although differential growth could explain the transformation of multipolar neurons to monopolar ones, it cannot explain the loss of the complicated secondary and tertiary branching patterns generated by larval neurons.

A parsimonious explanation of the transformation of neuronal shape is that it occurs by a process of retraction or pruning (Fig. 5). In this instance, supernumerary branches are eliminated from the surface of the cell body and axon. A similar phenomenon has been directly observed during the development of sensory collaterals in living frogs (Speidel, 1942). It also occurs in developing motor neurons in which axon collaterals are either withdrawn or phagocytized (Riley, 1977; Rosenthal and Taraskevich, 1977). Whatever the mechanics, there must be signals that trigger the implementation of pruning. Pruning may be an intrinsic property of the cells, such that they are preprogrammed to decrease the size of their axonal arborizations (Brown et al., 1976). Alternatively, pruning could be caused by extrinsic factors, like hormones or cell-cell interactions. Hormones can trigger dramatic changes in neuronal shape in widely varying species (Gurney, 1981; Levine and Truman, 1982), including Xenopus (Hoskins and Grobstein, 1984). Likewise, trophic interactions with either presynaptic neurons or target cells often effect changes in developing neurons (see Harris, 1974). Interestingly, at this time of development, the cardiac ganglion neurons are being wrapped by Schwann cells. Interactions with Schwann cells induce the morphological transformation of sensory neurons (Mudge, 1984) and accompany the removal of axons from polyneuronally innervated muscle (Korneliussen and Jansen, 1976; Rosenthal and Taraskevich, 1977). Thus neuron-Schwann cell interactions might represent a possible extrinsic stimulus for pruning. Finally, axonal pruning might result from competitive interactions between ganglion cells, all of which innervate a common target.

Several strategies are utilized by neurons in acquiring their mature shape. At one extreme are neurons that assume a directed growth, with little exploratory or collateral sprouting (Shankland, 1981; Kuwada and Kramer, 1983; Rubin, 1985). This "ballistic" growth differs from that seen, e.g., in the developing peripheral nervous system of vertebrates, where axons innervating muscles and autonomic neurons sprout many collaterals during early growth and subsequently withdraw them (Redfern, 1970; Lichtman, 1977; Lichtman and Purves, 1980; Johnson and Purves, 1981). Likewise, neurons from various regions of the vertebrate brain (Jhaveri and Morest, 1982; 


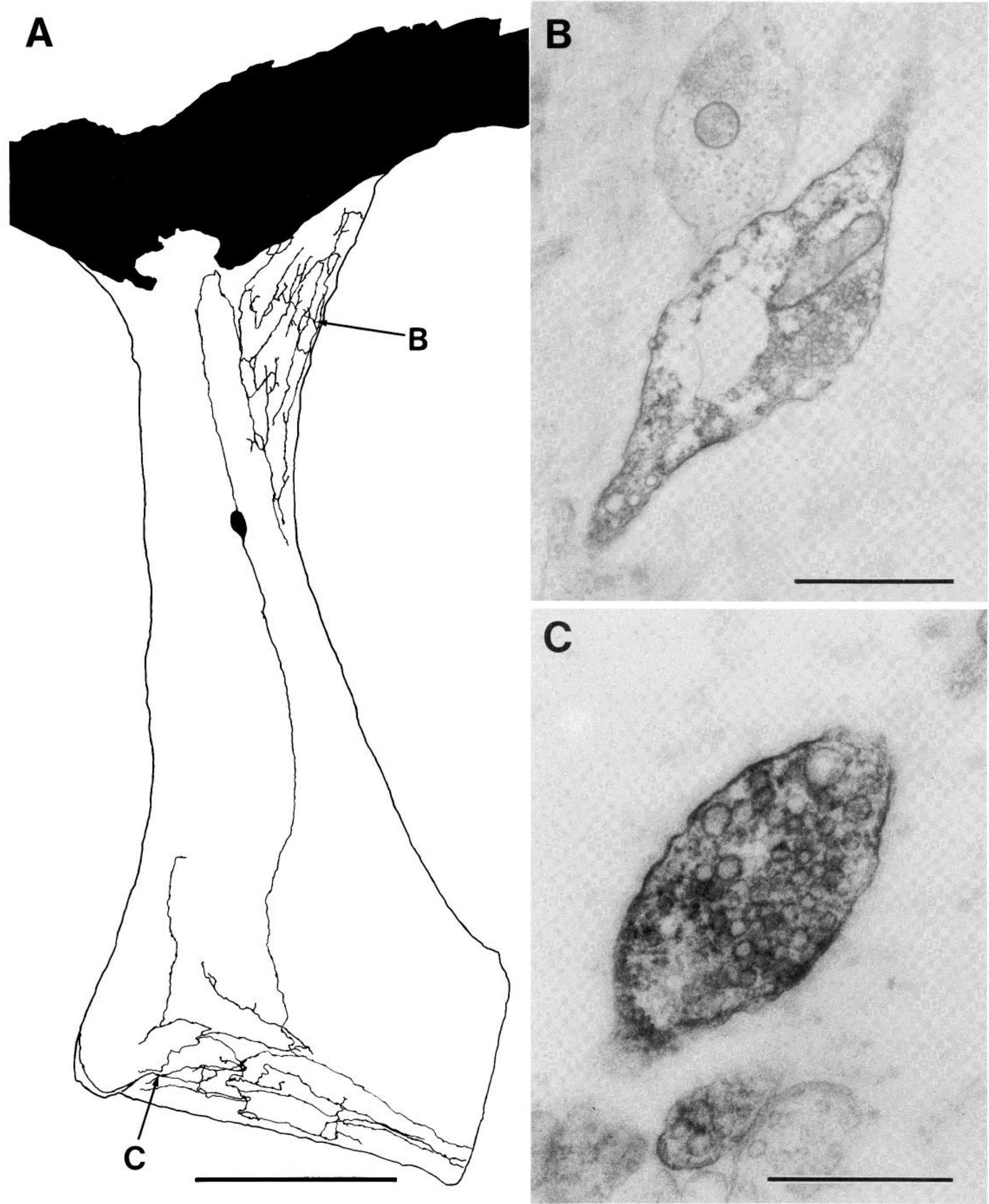

Figure 4. Ultrastructure of different axonal domains. A, Camera lucida drawing of a single, HRP-filled neuron in a larval atrium. The cell body is located centrally and gives rise to two processes, which extend to opposite poles of the atrium and arborize extensively. Both arbors support numerous varicosities, and electron microscopy of individual varicosities in the upper arbor $(B)$ and the lower arbor $(C)$ (arrows; identified in 2- $\mu \mathrm{m}$ sections) demonstrate that they contain synaptic vesicles and active zones. Both this neuron and two others examined were multiaxonal. Calibration: A, $200 \mu \mathrm{m} ; B, 1 \mu \mathrm{m} ; C, 0.5 \mu \mathrm{m}$. 


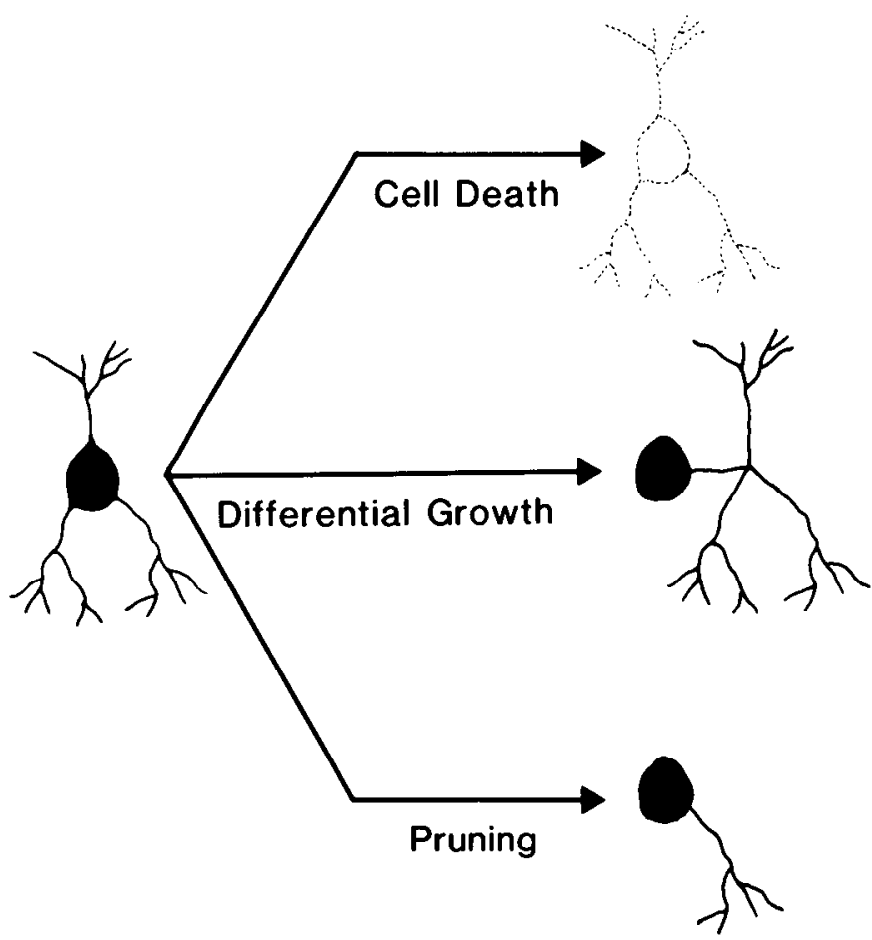

Figure 5. Possible morphogenetic mechanisms by which the transformation of larval neurons might occur. Selective cell death of multipolar neurons is a possibility, as is differential growth of the cell body away from its axons. The most parsimonious explanation is that excess branches are withdrawn or pruned from the cell body (see the text).

Jackson and Parks, 1982; Land and Lund, 1979), as well as identified nourons in invortebrates (Bentley and Toroian-Raymond, 1981; Wallace, 1984) go through a distinctive sequence of overgrowth followed by retraction of supernumerary processes. The purpose of this cycle is not clear; however, it also occurs in the mammalian visual system (Innocenti, 1981; Sretevan and Shatz, 1984) and is assumed to be the structural basis for the functional development of this system (Hubel and Wiesel, 1963; Shatz and Kirkwood, 1984). Cardiac ganglion neurons are cells that sprout dramatically during early development and subsequently eliminate supernumerary branches to form the mature cell shape.

These experiments reveal that the supernumerary processes of larval neurons are axons, which can extend to different areas of the target. If the stimulus for axonal outgrowth resides in the target, an entering axon would form collaterals, whereas the cell body of a neuron located within its target would form several axons. The subsequent reduction in the number of primary axons necessarily involves a major rearrangement of the neuronal cytoskeleton. Although such a rearrangement is often seen in the nervous system, the supernumerary processes are usually dendrites (Cajal, 1960; Hume and Purves, 1981). It is unclear why neurons generally support only a single axon while simultaneously supporting many dendrites. The occurrence of multiple axons in larval cardiac ganglion cells shows that there is no inherent restriction upon the number of axons a cell can have. However, the fact that supernumerary axons are eliminated suggests that although multiaxonal neurons can exist, they may represent an unstable state that is only transiently expressed by developing cells.

\section{References}

Bentley, D. and A. Toroian-Raymond (1981) Embryonic and postembryonic morphogenesis of a grasshopper interneuron. J. Comp. Neurol. 201:507518.

Brown, M. C., J. K. S. Jansen, and D. Van Essen (1976) Polyneuronal innervation of skeletal muscle in new-born rats and its elimination during maturation. J. Physiol. (Lond.) 261: 387-422.
Cajal, S. R. (1960) Studies on Vertebrate Neurogenesis, L. Guth, transl., Charles C Thomas, Springfield, IL.

Cowan, W. M., J. W. Fawcett, D. M. D. O'Leary, and B. B. Stanfield (1984) Regressive events in neurogenesis. Science 225: 1258-1265.

Gurney, M. E. (1981) Hormonal control of cell form and number in the zebra finch song system. J. Neurosci. 1: 658-673.

Harris, A. J. (1974) Inductive functions of the nervous system. Annu. Rev. Physiol. 36: 251-305.

Hartzell, H. C. (1980) Distribution of muscarinic acetylcholine receptors and presynaptic nerve terminals in amphibian heart. J. Cell Biol. 86: 6-20.

Heathcote, R. D., and P. B. Sargent (1983) Morphogenesis of cardiac ganglion neurons. Soc. Neurosci. Abstr. 9: 936.

Heathcote, R. D., and P. B. Sargent (1984) The genesis and differentiation of neurons in a frog parasympathetic ganglion. Dev. Biol. 105: 102-114.

Hoskins, S. G., and P. Grobstein (1984) Induction of the ipsilateral retinothalamic projection in Xenopus laevis by thyroxine. Nature 307: 730-733.

Hubel, D. H., and T. N. Wiesel (1963) Receptive fields of cells in striate cortex of very young, visually inexperienced kittens. J. Neurophysiol. 26: 9941002.

Hume, R. I. and D. Purves (1981) Geometry of neonatal neurones and the regulation of synapse elimination. Nature 293: 469-470.

Innocenti, G. M. (1981) Growth and reshaping of axons in the establishment of visual callosal connections. Science 212: 824-827.

Jackson, H., and T. N. Parks (1982) Functional synapse elimination in the developing avian cochlear nucleus with simultaneous reduction in cochlear nerve axon branching. J. Neurosci. 2: 1736-1743.

Jhaveri, S., and D. K. Morest (1982) Sequential alterations of neuronal architecture in nucleus magnocellularis of the developing chicken: A golgi study. Neuroscience 7: 837-853.

Johnson, D. A., and D. Purves (1981) Post-natal reduction of neural unit size in the rabbit ciliary ganglion. J. Physiol. (Lond.) 318: 143-160.

Korneliussen, H., and J. K. S. Jansen (1976) Morphological aspects of the elimination of polyneuronal innervation of skeletal muscle fibers in newborn rats. J. Neurocytol. 5: 591-604.

Kuwada, J. Y. and A. P. Kramer (1983) Embryonic development of the leech nervous system: Primary axon outgrowth of identified neurons. J. Neurosci. 3: 2098-2111.

Land, P. W., and R. D. Lund (1979) Development of the rat's uncrossed retinotectal pathway and its relation to plasticity studies. Science 205: $698-700$.

Levine, R. B., and Truman, J. W. (1982) Metamorphosis of the insect nervous system: Changes in morphology and synaptic interactions of identified neurones. Nature 299: 250-252.

Lichtman, J. W. (1977) The reorganization of synaptic connexions in the rat submandibular ganglion during post-natal development. J. Physiol. (Lond.) 273: $155-177$.

Lichtman, J. W., and D. Purves (1980) The elimination of redundant preganglionic innervation to hamster sympathetic ganglion cells in early post-natal life. J. Physiol. (Lond.) 301: 213-228.

Loewi, O. (1921) Uber humorale Ubertragbarkeit der Herznervenwirkung. Pflügers Arch. 189: 239-242.

McMahan, U. J., and S. W. Kuffler (1971) Visual identification of synaptic boutons on living ganglion cells and of varicosities on postganglionic axons in the heart of the frog. Proc. R. Soc. Lond. (Biol.) 177: 485-508.

Mudge, A. W. (1984) Schwann cells induce morphological transtormation of sensory neurons in vitro. Nature 309: 367-368.

Nieuwkoop, P. D., and J. Faber (1967) Normal Table of Xenopus laevis (Daudin), Elsevier/North-Holland Biomedical Press, Amsterdam.

Parzen, E. (1960) Modern Probability Theory and Its Applications. John Wiley \& Sons, Inc., New York.

Purves, D., and J. W. Lichtman (1980) Elimination of synapses in the developing nervous system. Science 210: 153-157.

Rakic, P. (1971) Neuron-glia relationship during granule cell migration in developing cerebellar cortex. A golgi and electronmicroscopic study in Macacus rhesus. J. Comp. Neurol. 141: 283-312.

Redfern, P. A. (1970) Neuromuscular transmission in new-born rats. J. Physiol. (Lond.) 209: 701-709.

Riley, D. A. (1977) Spontaneous elimination of nerve terminals from the endplates of developing skeletal myofibers. Brain Res. 134: 279-285.

Robson, J. A., and C. A. Mason (1979) The synaptic organization of terminals traced from individual labeled retinogeniculate axons in the cat. Neuroscience 4: 99-111.

Rosenthal, J. L., and P. S. Taraskevich (1977) Reduction of multiaxonal innervation at the neuromuscular junction of the rat during development. J. Physiol. (Lond.) 270: 299-310. 
Rubin, E. (1985) Development of the rat superior cervical ganglion: Ganglion cell maturation. J. Neurosci. 5: 673-684.

Shankland, M. (1981) Development of a sensory afferent projection in the grasshopper embryo. II. Growth and branching of peripheral sensory axons within the central nervous system. J. Embryol. Exp. Morphol. 64: 187209.

Shatz, C. J., and P. A. Kirkwood (1984) Prenatal development of functional connections in the cat's retinogeniculate pathway. J. Neurosci. 4: 13781397.

Speidel, C. C. (1942) Studies of living nerves. VII Growth adjustments of cutaneous terminal arborizations. J. Comp. Neurol. 76: 57-73.
Sretevan, D., and C. J. Shatz (1984) Prenatal development of individual retinogeniculate axons during the period of segregation. Nature 308: $845-$ 847

Stanfield, B. B. (1984) Postnatal reorganization of cortical projections: The role of collateral elimination. Trends Neurosci. 7: 37-41.

Sulston, J. E., and H. R. Horvitz (1977) Post-embryonic cell lineages of the nematode, Caenorhabditis elegans. Dev. Biol. 56: 110-156.

Tennyson, V. M. (1965) Electronmicroscopic study of the developing neuroblast of the dorsal root ganglion of the rabbit embryo. J. Comp. Neurol. 124: $267-318$

Wallace, B. G. (1984) Selective loss of neurites during differentiation of cells in the leech central nervous system. J. Comp. Neurol. 228: 149-153. 